PACS 32. 80. Rm; 05. 45. +b;

УДК 539. 184, 539. 192

\title{
SENSING STOCHASTICITY OF ATOMIC SYSTEMS BY ANALYSIS OF RECURRENCE SPECTRA IN AN CROSSED DC MAGNETIC AND AC ELECTRIC FIELDS
}

\author{
D. A. Korchevsky, I. M. Shpinareva and A. V. Ignatenko \\ Institute of Applied mathematics OSEU, P. O. Box 108, Odessa-9, 65009, Ukraine \\ Phone: +380-482-637227 E-mail: glushkov@paco.net
}

\begin{abstract}
SENSING STOCHASTICITY OF ATOMIC SYSTEMS BY ANALYSIS OF RECURRENCE SPECTRA IN AN CROSSED DC MAGNETIC AND AC ELECTRIC FIELDS

\section{A. Korchevsky, I. M. Shpinareva and A. V. Ignatenko}

A new method for sensing stochasticity and chaotic features of atomic and nano-optical systems in the crossed external electric and magnetic fields is developed and a dynamics of atomic systems in fields studied. As a basis for developing a new method for sensing stochasticity we use new quantum approach to calculation of the recurrence energy spectra and their statistical characteristics for atomic systems in crossed electric and magnetic fields in chaotic regime and some experimental data for checking obtained results. Some illustrations regarding the recurrence spectra and stochasticity in a number of atomic systems are presented.
\end{abstract}

Key words: sensing stochasticity, recurrence energy spectrum, electric and magnetic fields

\section{Анотація \\ ДЕТЕКТУВАННЯ СТОХАСТИЧНОСТІ АТОМНИХ СИСТЕМ НА ПІДСТАВІ АНАЛІЗУ РЕКУРЕНТНИХ СПЕКТРІВ У СХРЕЩЕННИХ ЕЛЕКТРИЧНОМУ І МАГНІТНОМУ ПОЛЯХ}

\section{Д. О. Корчевський, І. М. Шпінарева і Г. В. Ігнатенко}

Розроблено новий метод детектування стохастичності та елементів хаосу в атомних та нанооптичних системах у схрещених електричному та магнітному поля. В основі детектування лежить визначення рекурентних спектрів, їх статистичних характеристик для атомних систем у схрещених електричному та магнітному полях на основі нового теоретичного методу й використання експериментальних даних. В якості ілюстрації наведені дані по рекурентним спектрам та стохастичності для ряда атомних систем.

Ключові слова: детектування стохастичності, рекурентний енергетичний спектр, електричне і магнітне поле 


\title{
Аннотация \\ ДЕТЕКТИРОВАНИЕ СТОХАСТИЧНОСТИ АТОМНЫХ СИСТЕМ НА ОСНОВЕ АНАЛИЗА РЕКУРРЕНТНЫХ СПЕКТРОВ В СКРЕЩЕННЫХ ЭЛЕКТРИЧЕСКОМ И МАГНИТНОМ ПОЛЯХ
}

\section{Д. А. Корчевский, И. М. Шпинарева и А. В. Игнатенко}

\begin{abstract}
Разработан новый метод детектирования стохастичности и элементов хаоса в атомных и нанооптических системах в скрещенных электрическом и магнитном полях. В основе детек-тирования лежит определение рекуррентных спектров, их статистических характеристик для атомных систем в скрещенных электрическом и магнитном полях на основе нового теорети-ческого метода и использование экспериментальных данных. В качестве иллюстрации приведены данные по рекуррентным спектрам и стохастичности для ряда атомных систем.
\end{abstract}

Ключевые слова: детектирование стохастичности, рекуррентный энергетический спектр, электрическое и магнитное поле

\section{Introduction}

In last years a great interest attracts studying a dynamics of quantum systems in external electric and magnetic field [1-20]. It has been discovered that dynamics of these systems in external electromagnetic fields has features of the random, stochastic kind and its realization does not require the specific conditions. The importance of studying a phenomenon of stochasticity or quantum chaos in dynamical systems is provided by a whole number of technical applications, including a necessity of understanding chaotic features in a work of different electronic devices and systems, including the nanooptical ones.

Note that the effect of crossing the energy levels of atomic systems, provided by stochastic dynamics, in the external electric and magnetic fields is the basis for sensing very weak magnetic field strength. [19]. Besides, let us also mention that the interesting stochastic features may occur in the exciton dynamics in semiconductors as an exciton is similar in many features to the hydrogen atom, which has been considered as a prototype of the quantully chaotic system [6-8]. The Stark and Zeeman effects are separately considered in a great number of papers, but a behaviour of hydrogen and non-hydrogen atomic systems, the Wannier-Mott excitons in crossed electric and magnetic field is studied significantly less.

Rydberg atoms in strong external fields have been shown to be real physical examples of non-integrable systems for studying the quantum manifestations of classical chaos both experimentally and theoretically. To describe these phenomena, one has to make calculating and interpreting the recurrence spectra which is the Fourier transformation of a photo absorption spectrum $[16,17]$. Consequently, the recurrence spectrum provides a quantum picture of classical behaviour. Studies of recurrence spectra have led to observations of the creation of new orbits through bifurcation, the onset of irregular behaviour through core scattering and symmetry breaking in crossed fields $[1-6,17,20]$. In the past, many researchers have calculated the recurrence spectra of a Rydberg atom in an external field. But they only calculated the spectra in static electric or magnetic fields. In a recent experiment, the absorption spectrum of the lithium atom in a static electric field plus a weak oscillating field was measured and Haggerty and Delos gave some explanation for it theoretically (c. f. $[1,5,17])$. But as to the influence of an oscillating electric field on the absorption spectrum of the Rydberg atom in static magnetic field, none has given the calculation both experimentally and theoretically, besides the first classical estimate [17].

Our paper is devoted to carrying out a new scheme for sensing stochasticity and chaotic features of atomic (nano-optical) systems in the crossed external electric and magnetic fields and studying their dynamics in fields. As a basis for developing a new scheme for sensing stochasticity, we use new quantum approach to calculating the recurrence energy spectra for atomic systems in crossed fields in chaotic regime and some experimental data for checking obtained results. 


\section{The recurrence spectra for atomic systems in electric and magnetic field and sensing a sto- chasticity and chaotic features}

To calculate the energy spectra of atomic systems in the crossed external electric and magnetic fields we use a new approach, based on solution of the 2dimensional Schrödinger equation [20] for an atomic system in crossed fields and operator perturbation theory [18]. For definiteness, we consider a dynamics of the complex non-coulomb atomic systems in a static magnetic field and oscillating electric filed. Computer modelling and analysis of discovered non-regular structure of recurrence energy spectrum levels allows sensing the stochasticity and chaotic features. The hamiltonian of the multi-electron atom in a static magnetic field and an oscillating electric field is (in atomic units) is as follows:

$$
\begin{gathered}
H=1 / 2\left(p_{\rho}^{2}+l_{z}^{2} / \rho^{2}\right)+\gamma l_{z} / 2+(1 / 8) \gamma^{2} \rho^{2}+ \\
+(1 / 2) p_{z}^{2}+F_{1} z \cdot \sin (\omega t)+V(r)
\end{gathered}
$$

where the electric field and magnetic field $B$ are taken along the $\mathrm{Z}$-axis in a cylindrical system; $\gamma=\mathrm{B} / 2.35 \cdot 10^{5}$; We consider only the $\mathrm{m}=0$ state, thus $l_{z}=0 ; V(r)$ is a one-electron model potential, which takes the following general form:

$$
\begin{aligned}
& V(r)=-1 / r+V_{e l}, \\
& V_{e l}=V_{1}+V_{2}+V_{3} .
\end{aligned}
$$

Here $\mathrm{V}_{1}, \mathrm{~V}_{2}, \mathrm{~V}_{3}$ are correspondingly potentials of the $\mathrm{K}$-shell (as in a case of the $\mathrm{Li}$ atom), the $\mathrm{L}$ shell and other atomic core shells. These potentials are defined as follows (in a Coulomb units):

$$
\begin{gathered}
V_{1}(r)=(2 / Z r)\left[1-\exp \left(-2 b_{1} r\right)(1+r)\right], \\
V_{2}(r)=(8 / Z r)\left[1-\exp \left(-0,8 b_{2} r\right) \times\right. \\
\left.\times\left(1+0,6 r+0,16 r^{2}+0,032 r^{3}\right)\right], \\
V_{3}(r)=[(n-10) / Z r] \times \\
\times\left\{1-1 /\left[1+b_{3} r+\left(b_{3} r\right)^{2}+\left(b_{3} r\right)^{3}\right]\right\} .
\end{gathered}
$$

Here $\mathrm{Z}$ is a nuclear charge, and $b_{i}$ are free length parameters, which are chosen to give the energy spectrum of free atom. The hamiltonian obeys a classical scaling rule and can be written as:

$$
\begin{gathered}
\tilde{H}=\tilde{p}^{2} / 2+(1 / 8) \tilde{\rho}^{2}+ \\
+f \cdot \tilde{z} \cdot \sin (\tilde{\omega} \cdot \tilde{t})+V(r)=E(t) \gamma^{-2 / 3} .
\end{gathered}
$$

Here $\tilde{r}=r \gamma^{2 / 3}, \tilde{p}=p \gamma^{-1 / 3}, \tilde{f}=F_{1} \gamma^{-4 / 3}, \tilde{l}=l \gamma$, $\tilde{\alpha}_{i}=\alpha_{i} \gamma^{-2 / 3}$ and $\tilde{\omega}=\omega \gamma^{-1}$.

In the oscillating field, the electron energy $E(t)$ is not constant. We define $\varepsilon=E^{\text {out }} \gamma^{-2 / 3}$ as it leaves the atom. Usually it is useful to utilise the method of scaled recurrence spectroscopy to analyse the photo absorption amplitude as a function of the parameter $\gamma^{-1 / 3}$ while varying the laser frequency and external fields simultaneously in such a way that $\varepsilon$ and $f$ remain constant. To account for an electric field (it is supposed that the electric field is quite weak) it is possible to use the perturbation theory. A simultaneous account of electric and magnetic field is possible within a procedure of Burkova et al (c. f. review [11]). For solution of equations $(4,5,2)$ we constructed the finite differences scheme which is in some aspects similar to methods $[14,15,20]$. Under the differences solution (1), an infinite region is exchanged by a rectangular region: $0<\rho<L_{\rho}, 0<\mathrm{z}<L_{z}$. It has sufficiently large size; inside it a rectangular uniform grid with steps $h_{\rho}, h_{z}$ was constructed. The external boundary condition, as usually, is: $(\partial \Psi / \partial n)_{r}=0$. The knowledge of the asymptotic behaviour of wave function in the infinity allows to get numeral estimates for $L_{\rho}, L_{z}$. When $\omega \neq 0$, along axe $\mathrm{z}$, a wave function has an asymptotic of the kind as: $\exp \left[-(-2 E)^{1 / 2} r\right]$, where $(-E)$ is the ionization energy from stationary state to lowest Landau level. Then $L$ can be estimated as $L \sim 9(-2 E)^{-1 / 2}$. The more exact estimate is found empirically. The difference scheme is constructed as follows. The three-point symmetric differences scheme is used for second derivative on $z$. The derivatives on $\rho$ are approximated by $(2 m+1)$-point symmetric differences scheme with the use of the Lagrange interpolation formula differentiation. The eigen-values of hamiltonian are calculated by means of the inverse iterations method. The corresponding system of inhomogeneous equations is solved by the Thomas method. To increase an accuracy of the calculated eigen values, the Richardson extrapolation method on the grid step is used (c. f. $[14,15])$. To calculate the values of the photoionization cross section and width $G$ for resonances in spectra of atomic system in crossed electric and magnetic field one can use the modified operator perturbation theory method (see details in ref. $[18,19])$. Note that the imaginary part of the state energy in the lowest PT order is defined as follows:

$$
\operatorname{Im} E=G / 2=\pi<\Psi_{E b}|H| \Psi_{E s}>^{2}
$$

with the total Hamiltonian of system in an electric and magnetic field. The state functions $\Psi_{\mathrm{Eb}}$ and $\Psi_{\mathrm{Es}}$ are assumed to be normalized to unity and by the 
$\delta\left(\mathrm{k}-\mathrm{k}^{\prime}\right)$-condition, accordingly. The photoionization cross section can be define as follows:

$$
\begin{gathered}
\sigma^{F}=4 \pi^{2} \hbar \omega / 137 \times \\
\times \sum_{l, l^{\prime}}<0\left|r_{m}\right| \Psi_{l^{\prime}}>\left[\left\langle\Psi^{\prime}\right| \Psi>^{-1}\right]_{l l^{\prime}}<\Psi_{l}\left|r_{m}\right| 0>
\end{gathered}
$$

where $10>$ is the initial state of the atom, $r_{m}=z$ for $\pi$-polarized light and $r_{m}=(1 / \sqrt{2})(x \pm i y)$ for $\sigma$-polarization; $\left\langle\Psi_{l^{\prime}}{ }^{\prime} \mid \Psi_{l}\right\rangle-$ the overlap matrix of the set $\{\Psi\}$ (see details of its definition in [1] and cited ref. there). Other calculation details can be found in ref. [17-20].

\section{Results and discussion}

Let us give now an analysis of the sensing specific quantum chaotic features in the atomic systems in the crossed external electric and magnetic fields. We have used our approach to calculation of the energies for lithium atom in a crossed electric and magnetic fields. The transition from the lithium $3 \mathrm{~s}$ state to final states corresponding to the principle quantum numbers around $n=125$ and $m=0$ is considered. Following to ref. [16,17], because the ionic core produces important dynamical effects, we can split the whole space into two characteristic spatial regions: (1) The core region, where the laser field and the ionic core potential dominate while the external magnetic field, can be eliminated. It should be noted here that the standard semi classical closed orbit theory provides an efficient treating the motion of a Rydberg electron far from the nucleus, but it fails when the electron is close to the nucleus. As this region extends for only a few Bohr radii around the atomic nucleus, one must deal with this region by using a quantum mechanical method. (2) The external region, in which the influence of the laser field and the core potential are minimal, whereas the external magnetic fields and the Coulomb field dominate. This region typically lies beyond $30 \mathrm{Bohr}$ radii from the nucleus, so one can treat this region using standard semi classical methods or approximations to quantum approaches $[14,15,18-20]$. Using equation (2-4), we calculated the photo absorption spectrum of lithium in a magnetic field plus an oscillating electric field, with $B=4.7 \mathrm{~T}, F_{l}=10 \mathrm{~V} / \mathrm{cm}$ and $\omega=10^{8} \mathrm{~Hz}$. The result of calculation is presented in figure 1 . In figure 2 we present the results of calculation of the photo absorption spectrum of a lithium atom in a magnetic field without an electric field.
One can conclude from comparing the figures 1 and 2 that, when the oscillating field was added, the photo absorption spectrum was weakened greatly. It should be noted that this result is similar the analogous one, received within the standard closed orbit semi-classical calculation. In figures $3(a)-(d)$ we present the results of calculating the recurrence spectra of a lithium atom in a magnetic field plus an oscillating field, with $\varepsilon=-0.03, \bar{\omega}=0.32, \gamma^{-1 / 3}$ in the range $35-50$ and $f=0.000,0.0035,0.035$ and 0.07 , respectively. This data are similar to parameters of the semi-classical calculation [17]. As analysis of received data shows, when the value of $f$ increases, the strength of all the peaks decreases. Some recurrences dropped rapidly and vanished as $f$ increased; others remained even at much higher $f$. The results in this paper are very close to those of the ref. [17]. As the oscillating field gets stronger, some of the peaks re-appear, some more than once. Because when the

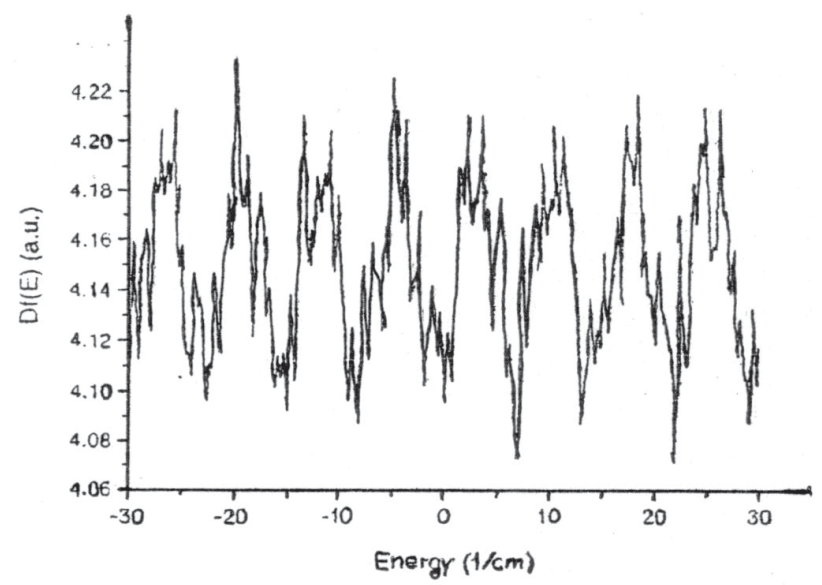

Figure 1. Absorption spectra of the $L i$ atom in magnetic field plus an oscillating electric field

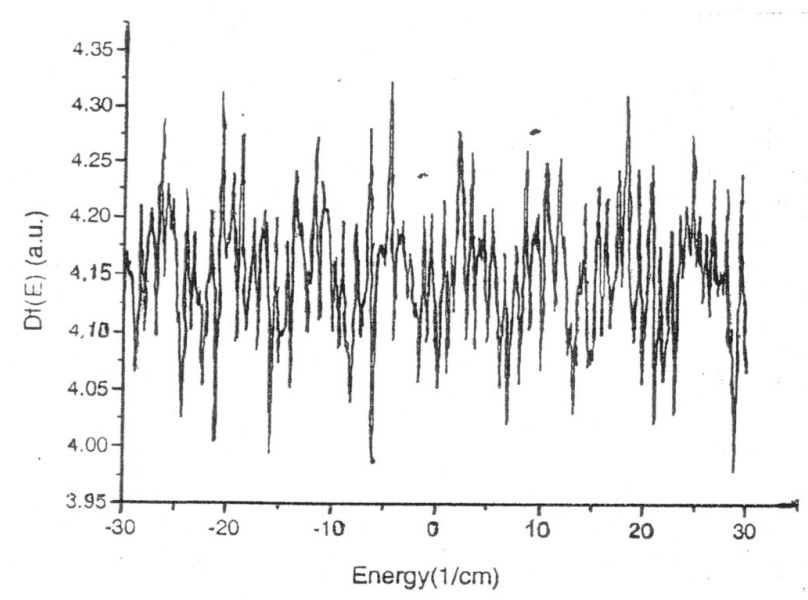

Figure 2. Absorption spectra of the $L i$ atom in magnetic field, $B=4.7 \mathrm{~T}$. The photo energy (horizontal axis) increases from left to right. 

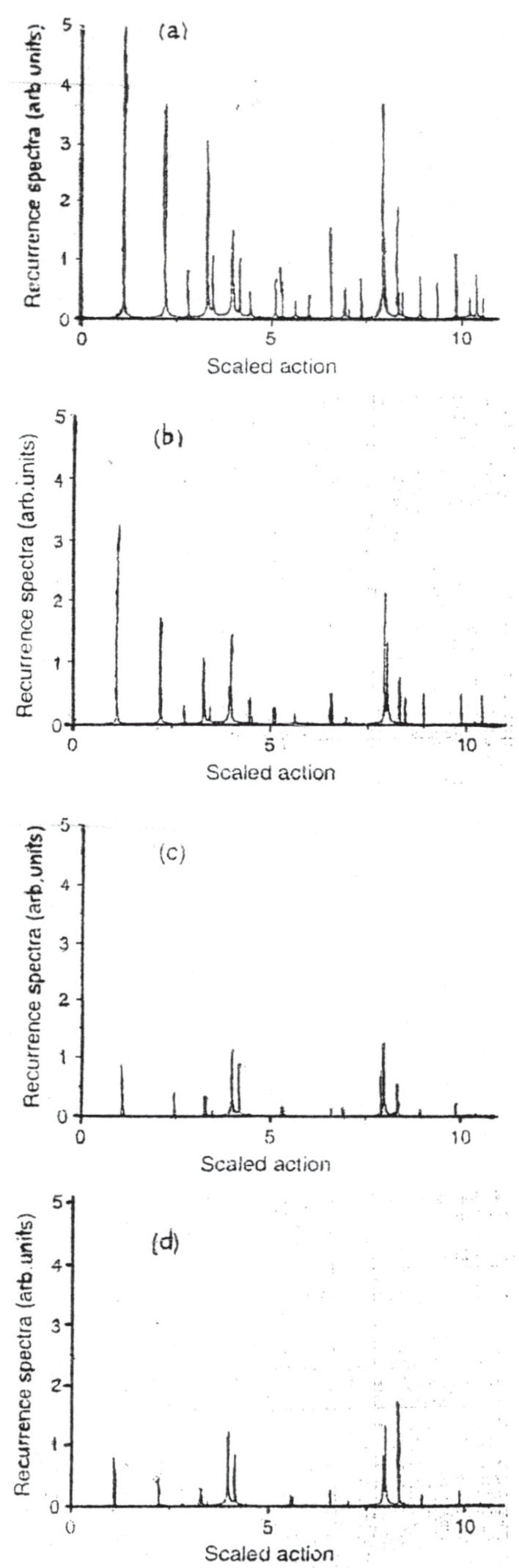

Figure 3. The recurrence spectra of the $L i$ atom in magnetic field plus an oscillating electric field:

(a) Scaled field $f=0.0$; this corresponds to the spectra without an electric field, (b) scaled field $f=0.0035$, (c) scaled field $f=0.035$ and (d) scaled field $f=0.07$. oscillating field is strong, one can not consider it as a perturbation, the method described in this paper [14] is no longer suitable. Note that besides the semiclassical closed-orbit theory in versions $[1,5,16,17]$, the other standard methods, for example, based on the perturbation theory [11,12], are not also acceptable for large values of field strengths. At the same time, our approach can be used even in a case of strong electric and magnetic field.

Availability of multiple resonances with little and super little widths in spectra of atomic systems in the external fields is described within a theory of quantum chaos and provided by interference phenomena and quantum fluctuations, which characterize the chaotic systems [1]. Calculated recurrence energy spectra and their statistical characteristics for atomic systems in crossed electric and magnetic fields allow quantitatively sensing a degree of stochasticity and chaos in the system. Obviously, the more interest calls for consideration of the similar phenomena in the nano-optical systems and also in the exciton spectra in semiconductors.

\section{References}

1. Gutzwiller M.,Chaos in Classical and Quantum Mechanics. - N. - Y.:Springer-Verlag, 1990. 720 p.

2. Kleppner D., Chun-Ho I., Welch G. R., Irregular Atomic Systems and Quantum Chaos, Ed. J. C. Gay, N-Y.: Kluwer, 1990. - P. 21-48.

3. Dupret K., Zakrzewski J., Delande D.,Resonances in the Diamagnetic Rydberg Spectrum: Order and Chaos// Europhys. Lett. - 1995. - V. 31(5). P. 251-256.

4. Gasati G., Guarneri I., Mantica G., Classical Stabilization of periodically kicked hydrogen atoms// Phys. Rev. A. - 1994. - V. 50(6). - P. 5018-5024.

5. Dando P. A., Monteiro T. S. Atoms in Static Fields: Chaos or Difraction// In: Photonic, Electronic, Atomic Collisions, Eds. W. Aumyr, H. Winter. - World Sci. Pub.,Singapore. - 1997. - P. 621630.

6. Benvenuto F., Casati G., Shepelyansky D. L., Rydberg Stabilization of atoms in strong fields: "magic"mountain in chaotic sea// Z. Phys. B. 1994. - V. 94. - P. 481-486.

7. Excitons, Eds. Rashba E. I., Sterdge M. D. - N. Y.: Elseiver, 1995. - 390p.

8. Kulakovsky V., Pikuz. E., Timofeev V. F., Multiexciton complexes in semiconductors// Usp. Fys. Nauk. - 1985. - V. 135(1). - P. 237-274.

9. Delone N. B., Krynov V. P. Atom in a strong light field. - M.: Atomizdat, 1994. - 370p. 
10. Landau L. D., Lifshits E. M. Quantum Mechanics. - M.: Nauka, 1989.

11. Lisitsa V. S., New in Stark and Zeemane effects for hydrogen atom// Usp. Phys. Nauk.. - 1987. - V. 153(3). - P. 379-422.

12. Popov V. S., Karnakov B. M., Moor V. D., Ionization of atoms in electric and magnetic field and methos of imaginary time// JETP. — 1998. - V. 113(5). - P. 1579-1605.

13. Ivanov M. V., Grid calculation of energies and widths for ground state of $\mathrm{H}$ molecular in string electric field// Opt. Spectr. — 1994. — V. 78(5). P. 711-713.

14. Ivanov M. V., Schnelcher P., Ground States of $\mathrm{H}, \mathrm{He}, \ldots, \mathrm{Ne}$ and their singly positive ions in strong magnetic fields: the high-field regime// Phys. Rev. A. - 2000. - V. 61. - P. 2251-2263.

15. Kuklina I. V., Shevchuk V. G., H-like and He-like Systems in Superstrong magnetic field: Numeral Calculation//Uzhgorod Univ. Sci. Herald. Ser. Phys. - 2000. - V. 8(2). - P. 361-365.
16. Cheng T., Liu J., Chen S., Guo H. Rydberg atoms in parallel microwave and magnetic fields- classical dynamics// Phys. Lett. A. - 2000. — V. 265. P. 384-390.

17. Wang D., Din S., Liu S. Influence of oscillating electric field on the recurrence spectra of a Li Rydberg atom in strong magnetic field// J. Phys. B:At. Mol. Opt. Phys. - 2003. - V. 36. - P. 42254232.

18. Glushkov A. V., Ivanov L. N., DC Strong-Field Stark-Effect: consistent quantum-mechanical approach // J. Phys. B:At. Mol. Opt. Phys. — 1993. V. 26,N16. - P. L379-388.

19. Glushkov A. V., Ambrosov S. V. et al, Resonances in Quantum Systems in strong external fields: Consistent Quantum Approach// Journ. Techn. Phys. - 1997. - V. 37(2). - P. 215-218.

20. Korchevsky D. A. Energy spectra of Wannier-Mott excitons and hydrogen atom in an crossed dc electric and magnetic fields//Photoelectronics. - 2003. - V. 13. - P. 131-136. 